\section{O Inquérito Policial em \\ Questão - Situação atual e \\ a percepção dos Delegados \\ de Polícia sobre as \\ fragilidades do modelo \\ brasileiro de investigação \\ criminal}

Rodrigo Ghiringhelli de Azevedo ${ }^{1}$

Fernanda Bestetti de Vasconcellos ${ }^{2}$

Resumo: O presente artigo discute, inicialmente, o modelo de investigação criminal pré-processual adotado no Brasil, tendente a reforçar um perfil burocrático e bacharelesco em detrimento das atividades de investigação policial. São discutidas as relações institucionais que se estabelecem entre a Polícia Civil e as demais instituições do Sistema de Segurança Pública e Justiça Criminal e conclui-se que a falta de integração sistêmica entre os diferentes âmbitos da Justiça Criminal acaba por multiplicar as fontes de tensão entre os seus agentes e compromete a eficiência do sistema como um todo. Por fim, são apresentados trechos de entrevistas realizadas com Delegados de Polícia atuantes na cidade de Porto Alegre - RS, no intuito de apreender as percepções desses operadores do Sistema Penal a respeito dos dilemas enfrentados para a produção da investigação, tanto na relação com as demais instituições, quanto pelas precariedades materiais e humanas que se evidenciam na Polícia Civil gaúcha.

Palavras-chave: Inquérito Policial; Investigação Criminal; Delegados de Polícia; Processo Penal.

\section{O Inquérito Policial}

m praticamente todos os países, o processo penal propriamente dito é precedido de uma fase preliminar ou preparatória destinada a apurar indícios da materialidade e da autoria do delito. A atribuição de conduzir essa fase preliminar pode ser exclusivamente da polícia, como no sistema inglês do Ministério Público, como no chamado sistema continental, que dispõe da polícia
Recebimento:

1. Sociólogo, Professor dos Programas de Pós-Graduação em Ciências Sociais e em Ciências Criminais da PUCRS.

2. Socióloga, Doutoranda em Ciências Sociais pela PUCRS. 
judiciária para aprofundar as investigações, ou ainda, de um juiz de instrução, como no processo penal francês e espanhol.

No Brasil, encontramos uma solução mista para essa fase preparatória da persecução penal: cabe à polícia a investigação preliminar e a produção de um relatório juridicamente orientado do resultado dessas investigações. A responsabilidade pela condução do inquérito cabe a uma autoridade policial - o delegado de polícia, que recebe essa delegação do Chefe de Polícia. A ambivalência aqui resulta da fusão das prerrogativas de 'investigar' e de 'formar a culpa', de iniciar, através do indiciamento e da tomada de depoimentos, uma etapa que, na prática, adquire um status pré-instrucional, sob um enquadramento funcional administrativo e não judiciário (MISSE, 2010, p. 10-11). Combinando o estatuto de neutralidade da investigação policial com a potencial atribuição e formação da culpa, o inquérito policial não tem parâmetros de comparação com outros modelos de investigação preliminar.

Diante da precariedade de meios, boa parte das previsões legais que estabelecem os procedimentos a serem realizados durante o inquérito policial não são seguidos, tendo como justificativa a necessidade de lidar com as dificuldades cotidianas e responder à demanda imediata. As práticas correntes atravessam a fronteira de uma legalidade considerada antiquada, inquisitorial, quando não autoritária, seguindo em direção a um tipo de "ilegalidade prática", uma lógica em uso justificada pela eficiência. Se o inquérito, em seu formato oficial, passa a ser um entrave, criam-se alternativas práticas para dar eficiência a algo que, de outro modo, não atenderia à imensa demanda recebida pela polícia. No entanto, essa "ilegalidade eficiente" tanto diminui as garantias de direitos dos acusados, quanto, também, não tem se demonstrado capaz de aumentar a capacidade investigativa da polícia (MISSE, 2010, p. 13).

No início dos anos 90, Roberto Kant de Lima desbravava o tema da atuação da polícia na cidade do Rio de Janeiro e, sobre o lugar do inquérito policial no processo de criminalização, afirmava:

(...) o sistema judicial restringe significativamente a atividade judiciária da polícia ao situá-la em plano inferior na hierarquia judicial. (...) Tantas restrições aos efeitos das investigações policiais justificam-se pela característica inquisitorial, isto é, unilateral, inquest-like, da ação policial. Ela é, por definição, preliminar e não produz consequências definitivas. (KANT de LIMA, 1995, p. 36).

No entanto, para Kant de Lima, a polícia reage a essa posição de subalternidade jurídica, uma vez que lhe cabe, de fato, a tarefa de selecionar quais indivíduos são qualificados para gozar dos direitos constitucionais e quais não são. 
Desempenhando esse papel, as práticas policiais discricionárias permitem ao Sistema Judicial permanecer "inocente" de quaisquer práticas discriminatórias e injustas na aplicação da lei. Quanto à polícia, transforma o seu estigma em identidade e projeta os mecanismos de estigmatização sobre a população submetida à sua vigilância.

Como já demonstraram os estudos de fluxo da Justiça Criminal no Brasil, o principal gargalo do sistema encontra-se na passagem entre a polícia e o Ministério Público, onde se perde a maior parte das ocorrências. O principal bloqueio, portanto, não está no Judiciário, mas na passagem do inquérito policial para o Ministério Público. Nesse sentido, entende-se por que as adaptações práticas admitidas no sistema não se têm revelado tão eficientes. Não se trata aqui, simplesmente, de denunciar arbitrariedades e corrupção no funcionamento desse sistema, facilitadas pelo caráter extraoficial e obscuro dessas práticas. O que ocorre na gestão prática do inquérito policial são desvios da lei geridos institucionalmente, através de acordos e pactos informais que envolvem a polícia, o Ministério Público e até o Judiciário, e que são mantidos em nome da racionalidade do sistema.

O inquérito policial forma culpa. Seu caráter administrativo, na prática, toma forma de uma pré-instrução criminal, dominante na etapa judiciária, embora não garanta, na prática, o contraditório e nem as garantias individuais do acusado. Tal como colocado, o modelo do inquérito policial reforça um perfil burocrático e bacharelesco em detrimento das atividades de investigação policial. Diante da alegação de que o problema seria a falta de estrutura, constata-se que, ainda que a estrutura fosse mais adequada, se poderia questionar o modelo atual pelas dificuldades de integração entre as polícias e destas com os demais órgãos do Sistema de Justiça Criminal.

\section{Relações institucionais e práticas policiais}

Desde a redemocratização, a demanda pelos serviços prestados pelo Poder Judiciário, tanto no âmbito civil, quanto no criminal, cresceu significativamente no Brasil. Especificamente no âmbito da justiça penal, a situação tornou-se dramática. Com o expressivo crescimento da criminalidade urbana, a partir da década de 80, a defasagem do sistema penal e prisional tornou-se evidente (ADORNO, 1994), dando margem, paradoxalmente, ao aumento do arbítrio policial e à expansão dos mecanismos informais de atuação da polícia. Nesse panorama, a existência de um Estado de Direito para amplos setores da população brasileira não se efetivou, exigindo a realização de reformas legais e institucionais que deem conta dessa problemática. 
Com relação ao trabalho da Polícia Civil que, no Brasil, desempenha o papel de polícia judiciária nos estados, os resultados obtidos através de uma pesquisa realizada entre os anos de 2008 e 2009, em cinco diferentes capitais (Rio de Janeiro, Brasília, Porto Alegre, Recife e Belo Horizonte), demonstraram a existência de práticas, interesses e valores distintos e, muitas vezes, conflitantes no que se refere ao cotidiano de policiais civis, defensores, promotores e juízes (MISSE, 2010, p. 16-18).

A realização da investigação policial e elaboração do inquérito são tarefas que exigem uma amplitude de saberes. Para além do que a letra da lei explicita sobre os procedimentos de investigação preliminar ao processo penal, são necessários recursos "relacionais" desenvolvidos por policiais civis, no sentido de superar dificuldades existentes, sejam elas pela falta de recursos materiais e humanos para a realização da investigação de todos os crimes que chegam ao conhecimento da Polícia Civil ou, mesmo, pelas dificuldades de comunicação entre os diferentes operadores do Sistema de Justiça Criminal. Como esclarece Michel Misse,

Saber fazer as conexões, conhecer as pessoas, entender relações, ter os contatos, poder vincular dados de pessoas e coisas de diferentes lugares, com processos e inquéritos, são um capital importante que gera informação valiosa. (MISSE, 2010, p. 95)

A forma como a investigação policial é conduzida e o modo como é produzido o inquérito nas delegacias, apresenta oscilações entre o legal e o ilegal nas práticas policiais. A construção do inquérito vai depender, na prática, do controle das informações obtidas no decorrer das investigações. Nesse sentido, pode-se pensar, seguindo Misse, em uma "construção social do crime no Brasil":

(...) no sistema inquisitorial a incriminação se sobrepõe à acusação e ganha autonomia plena, impedindo que as partes envolvidas negociem legalmente e abrindo, em conseqüência, espaço para um mercado clandestino de trocas de bens ou serviços políticos, privadamente apropriados. Não se trata apenas de uma "corrupção" de costumes, ou de um "desvio", mas da constituição de uma ordem ilícita funcional para o tratamento, encaminhamento e solução de contradições sociais em escala microssocial, interindividual, algo como uma "ordem legítima" paralela, em convivência contraditória, mas não necessariamente conflitual, com a ordem legítima legal, e que se baseia na legitimação "tácita" desse tipo de trocas e desse tipo de mercado. (MISSE, 2008, p. 18-19)

No decorrer da pesquisa, foi possível perceber que, quando questionados sobre a função do inquérito policial, os diferentes integrantes do Sistema de 
Justiça Criminal observam que o mesmo cumpre uma função chave para toda ação penal, já que é a partir dele que a mesma é iniciada e dele depende, em grande medida, o resultado do processo criminal. $\mathrm{O}$ inquérito policial, por sua natureza, acaba configurando um primeiro juízo do Estado acerca de um evento criminoso, uma vez que a versão ali explicitada tende a ser reproduzida na persecução penal, da denúncia do Ministério Público à formação da convicção pelo juiz. Na percepção de diferentes operadores do Sistema de Justiça Criminal, assim como uma "boa investigação", um "bom inquérito" é aquele que propicia a reconstituição de um delito de forma detalhada, "não deixando dúvidas" quanto aos elementos centrais (autoria, motivação e circunstâncias). Para alguns delegados, "a prova da excelência de um inquérito está na confirmação das conclusões da investigação pelo veredito do juiz" (RATTON, 2010, p. 267).

É importante referir que, do ponto de vista normativo, a fase pré-processual, na qual a elaboração do inquérito policial está colocada, deve ter as ações direcionadas para o apontamento da probabilidade de materialidade e de autoria de um crime, não sendo cabível, nesse momento, a produção de provas, que deve ser feita em juízo (sendo excetuados os exames periciais), preservando, desse modo, todas as garantias do acusado (LOPES Jr., 2006). Na prática, o inquérito policial parece cumprir o papel de principal referência dos operadores do Sistema de Justiça Criminal no decorrer da instrução processual e na formulação de sentenças (VARGAS, 2010, p. 184).

A realização das investigações para a produção do inquérito policial gera algumas tensões entre os diferentes âmbitos do Sistema de Justiça Criminal. A discricionariedade policial, utilizada para decidir que tipo de ocorrência gerará ou não um inquérito policial e, quando produzido, decidir o que ali constará ou não, é apontada por alguns operadores do Sistema de Justiça Criminal como um elemento que gera consequências em todo o fluxo da Justiça. Nesse sentido, promotores e juízes concordam com a necessidade de adoção de estratégias de regulamentação e controle mais efetivas sobre o trabalho da Polícia Civil (RATTON, 2010, p. 288-289), uma vez que, diante do aumento da demanda, é cada vez maior a distância entre os delitos registrados e os que são efetivamente investigados, obrigando os policiais a desenvolverem critérios informais para selecionar os casos que serão priorizados.

A falta de integração sistêmica entre os diferentes âmbitos da Justiça Criminal acaba por multiplicar as fontes de tensão entre os seus agentes e compromete a eficiência do sistema como um todo. Um exemplo das dificuldades existentes pode ser ilustrado pelas tensões entre Polícia Judiciária e Ministério Público:

(...) As análises de fluxo de tempo, das entrevistas e dos grupos focais demonstraram, em período recente, a desarticulação profunda a que 
historicamente estiveram submetidos a Polícia Civil, o Ministério Público, e o Judiciário. A inexistência de padrão de registro unificado para os casos, o descompasso entre as formas organizacionais das diferentes agências (...) e as deficiências e incapacidades históricas de comunicação entre todas as agências são alguns dos indicadores dessa desarticulação. A própria ideia de Sistema de Justiça Criminal parece mais um artifício conceitual (e quase retórico) utilizado por nós, cientistas sociais, para referirmo-nos a um objeto por vezes inatingível empiricamente. (RATTON, 2010, p. 293294)

Mesmo que alguns delegados entendam que uma maior aproximação e confiança entre a Polícia Civil e o Ministério Público favoreceria o andamento do processo penal, o que se observa na prática é que a devolução de inquéritos (ocorrida após a conclusão do inquérito policial pela polícia, no caso do Ministério Público acreditar ser necessário constar algum outro elemento investigativo ausente na peça) ocasiona uma forte tensão na relação entre o Ministério Público e os policiais. $\mathrm{O}$ argumento apontado por delegados e escrivães é o de que, em muitos casos, os inquéritos acabam sendo devolvidos à Polícia Civil por questões muito simples, fazendo com que a percepção dos policiais seja a de que o Ministério Público está mais interessado em cobrar da Polícia Civil, com todas as suas carências, ao invés de solidarizar-se com os problemas vividos pelos integrantes da instituição e com suas condições adversas de trabalho (RATTON, 2010, p. 291).

As tensões entre os operadores do Sistema de Justiça Criminal não aparecem apenas entre os diferentes âmbitos, mas também entre os integrantes da instituição policial. Como anteriormente citado, a elaboração do inquérito policial exige diferentes saberes, os quais, muitas vezes parecem estar em conflito. Há uma variedade de papéis e atividades desenvolvidos dentro das delegacias de polícia que requerem diferentes tipos de conhecimento (administrativo, investigatório, jurídico), e a distribuição desses papéis e suas respectivas atividades é marcada por forte hierarquia institucional. As atividades realizadas pelos servidores situados na parte superior dessa hierarquia costumam estar fundamentadas e legitimadas pelo conhecimento jurídico, o qual possibilita a realização de relatórios formalmente capazes de produzir material legítimo para a instrução de processos criminais. As demais atividades realizadas pela polícia, como policiamento comunitário, atendimento a grupos específicos, administração de conflitos e mesmo o trabalho de investigação acabam sendo consideradas pelos integrantes da instituição como atos secundários, de menor importância, e os profissionais que executam tais funções ocupam um local inferior na hierarquia policial. Para Arthur Costa,

A confecção do inquérito policial, e mais especificamente do seu relatório 
final parece ser a principal atividade numa delegacia de polícia. Trata-se, portanto, da imposição de um tipo de saber, típico do campo jurídico, a uma instituição pertencente ao campo policial. (COSTA, 2010, p. 234)

\section{As relações institucionais na percepção dos policiais (delegados)}

Os trechos de entrevistas a seguir reproduzidos foram coletados no âmbito da pesquisa "O Inquérito Policial no Brasil: uma pesquisa empírica", coordenada por Michel Misse, realizada em cinco capitais brasileiras. As entrevistas aqui transcritas foram realizadas na cidade de Porto Alegre, com delegados atuantes naquela capital, em delegacias distritais e especializadas, no período de dezembro de 2008 a maio de 2009.

O problema da relação entre as polícias civil e militar é bastante conhecido e remete ao debate sobre a estrutura das polícias no Brasil. No modelo adotado pela Constituição de 88, há uma divisão do ciclo policial, sendo uma polícia militarizada a responsável pelo policiamento ostensivo e outra, judiciária, encarregada da investigação criminal. As críticas ao caráter militarizado das polícias militares são conhecidas, por representar um resquício de vínculo com as forças armadas, absolutamente incompatível com o desempenho de atividades de segurança pública. A militarização causa descontentamento entre os próprios policiais, especialmente dos que atuam no policiamento de rua, pertencentes aos escalões mais baixos e mais numerosos da polícia, por determinar relações de trabalho diferenciadas em relação aos demais servidores públicos, impossibilidade de questionamento das ordens superiores, obrigação de realizar atividades de acordo com a vontade do superior, mesmo que em desvio de função, etc. A questão do ciclo completo de polícia também vem sendo debatida, especialmente a partir da experiência de produção de Termos Circunstanciados por algumas polícias militares, encaminhando o caso diretamente para o Poder Judiciário.

De qualquer forma, há um descontentamento generalizado com relação à estrutura policial vigente, pelos problemas de relacionamento entre as instituições, duplicação de gastos e estruturas, incompatibilidade com o desenvolvimento de uma polícia moderna, etc.

Para a maioria dos entrevistados, a ideia da unificação é bem aceita, embora não haja, da parte deles, confiança no sentido de que uma reforma dessa envergadura será levada adiante:

Eu acho um absurdo duas polícias, primeiro jamais vai haver integração, e isso pode entrar o governante que queira entrar, jamais vai haver integração. O que temos que ter? Polícia única! Qual é a 
3. Atendendo à necessidade antiga de uma ampla reforma na letra da Lei Penal, em 07 de dezembro de 2010, foi aprovado pelo Senado brasileiro o projeto de reformulação do texto do Código de Processo Penal. Dentre as modificações textuais realizadas pelo Senado, destacam-se a tentativa de real implementação de um sistema acusatorial, mudanças na realização do inquérito policial e a previsão da atuação de um juiz de garantias no decorrer do processo de investigação criminal. Uma das novidades trazidas pelo projeto de reforma do Código de Processo Penal é a criação da figura do juiz de garantias. Dada a necessidade de neutralidade do operador jurídico durante a realização de um julgamento, o juiz de garantias passaria a atuar no decorrer da operacionalização do inquérito, separando as funções de acompanhamento das investigações e julgamento em primeira instância, atualmente realizada por um mesmo magistrado. De acordo com o texto aprovado pelo Senado, o juiz de garantias teria como objetivo principal o controle das ações da Polícia Judiciária no decorrer da investigação policial, garantindo a legalidade e o respeito aos direitos tendência mundial? É a desmilitarização da polícia! Só que infelizmente o lobby da Polícia Militar é muito forte, muito maior do que o nosso, então eu acredito que jamais vai ocorrer essa unificação, que, para mim, seria o mais correto, em virtude desse lobby, em especial da Polícia Militar. Não que nós da Polícia Civil não tenhamos interesses contrários à unificação, tem muitos policiais civis que não querem porque muitos delegados em havendo unificação acreditam que nós vamos perder espaço de abrangência jurídica, só que eu não penso assim, nós temos que ser cabeça mais aberta, e a Polícia Militar não quer perder algumas garantias que tem graças a ser Polícia Militar. Mas o correto seria a unificação, porque duas polícias, dois setores de inteligência, tu vai num local de crime hoje tem dez policiais militares e cinco policiais civis, o que for colhido por eles de informações não vai chegar até nós e o que a gente colhe não chega a eles, muitas informações que chegam para nós seriam importantes para o trabalho deles, e muitas informações que chegam para eles seriam muito bem utilizadas para nossa investigação, então nessa troca de informações se perde muito, poderia ter um prédio só com as duas polícias unificadas, o ideal seria a unificação.

Eu vou dar a minha opinião, eu acho que tem que unificar. Minha opinião é pela unificação das polícias. Essa dicotomia não funciona. Onde eu trabalhei nunca tive problema com a Brigada, eles fazem o trabalho deles e eu faço o meu, e ficamos nos policiando. Mas eu vejo o que, uma coisa é eu ter uma experiência pessoal, eu agir assim, o comandante fulano agir assim e tal, e outra coisa é as instituições. Se fala hoje em dia aí na municipalização da segurança, se fala no ciclo completo de polícia com as polícias municipais, olha, isso vai ser a pior coisa que pode ter, várias polícias concorrendo livremente, um vai atrapalhar a investigação do outro, e aí nós vamos estar nos matando na rua, um atrapalhando o serviço do outro, em razão disso tudo eu vejo que o melhor seria a unificação das polícias uma polícia só. Claro que um segmento vai fazer policiamento, um segmento vai fazer a polícia comunitária, um segmento vai fazer a investigação, coordenados por uma pessoa só, e aí tem acesso normal a tudo isso aí e tal.

De maneira geral, os delegados apontam dificuldades para a investigação criminal que seriam oriundas da estrutura legal e da falta de agilidade e compreensão por parte do Poder Judiciário. O discurso articulado por eles acaba por se mostrar contraditório, pois por um lado identificam essas dificuldades que seriam derivadas da judicialização dos procedimentos de investigação, que teriam de passar pelo crivo do juiz, mas ao mesmo tempo reconhecem que não teria como ser diferente em um Estado Democrático de Direito ${ }^{3}$. A questão aparece mais como uma espécie de desabafo pelo fato de que as iniciativas da 
polícia não podem ser tomadas sem a chancela do Judiciário:

Por fim eu diria que é uma dificuldade também o nosso sistema, que eu sou um crítico do nosso sistema penal, sistema processual da maneira como está posto. A cada dia se verifica mais dificuldades na investigação em razão dessa sistemática legal, e ali gosto sempre de pontuar com exemplos concretos, a investigação é praticamente ela toda judicializada, não se faz nada sem que passe sob o crivo do contraditório, não, mas a prisão em flagrante, também, a prova de prisão em flagrante vai remeter ao juiz, enfim, vai verificar se ela é legal ou ilegal, essa coisa toda, então até na prisão em flagrante tem o crivo do juiz. E o restante, a expedição do mandado de busca e apreensão da res furtiva para materializar depende do judiciário, e aí depende muitas vezes, na maioria das vezes foge à tua competência, aí tu entra com uma representação no judiciário e leva vinte, vinte e cinco dias para tu receber de volta, e o critério da oportunidade e conveniência daquela diligência, muitas vezes se perde por aí também. O êxito da investigação criminal está intimamente ligado à celeridade da prestação jurisdicional, mas em função da judicialização do inquérito, tudo depende do judiciário.

A Constituição Federal de 1988 determina, em seu Art. 129, inciso VII, que o Ministério Público realize o controle externo da atividade policial, na forma definida pela legislação complementar, incluindo-se nesse âmbito o acompanhamento de todos os estágios da atividade policial, o exame de documentos e procedimentos relacionados com as investigações e a denúncia dos casos de crimes, abusos e violações praticados contra os direitos individuais. No Rio Grande do Sul, essa atribuição foi regulamentada pela Lei Complementar 11.578/2001.

No entanto, até hoje essa atribuição não vem sendo desempenhada da forma que se esperaria, tendo em vista a importância da atividade de controle externo da polícia e a vocação institucional do Ministério Público, enquanto órgão independente em relação ao Poder Executivo para o exercício deste controle. Conforme Lemgruber, Musumeci \& Cano, em pesquisa publicada no ano de 2003 sobre o tema,

Na prática, porém, essas vastas atribuições de direito nunca foram exercidas de fato, salvo em casos isolados, representados por "células" ativistas dentro de alguns Ministérios Públicos estaduais, que direcionam esforços específicos para a redução da violência e dos abusos cometidos pela polícia. Comparado à sua incisiva atuação como "fiscal da lei" em outros setores da administração estatal, sobretudo monitorando e denunciando casos de corrupção, o desempenho do Ministério Público no controle externo das polícias e no combate à violação de direitos humanos até do investigado. $\mathrm{O}$ juiz de garantias passaria a ser o operador jurídico com atribuições de decidir sobre a utilização de medidas de prisão preventiva, quebra de sigilo, interceptação telefônica do investigado, etc. 
hoje ficou muitíssimo aquém do papel que a Constituição de 1988 Ihe conferiu - como, aliás, seus próprios integrantes reconhecem amplamente. (LEMGRUBER, MUSUMECI \& CANO, 2003, p. 123)

Segundo eles, haveria dois problemas para o exercício efetivo dessa função. 0 primeiro seria a dificuldade de precisar o próprio conceito de "controle externo", o que faz com que a maioria dos promotores interprete a sua função de forma "minimalista", limitando-se à revisão técnica das evidências apresentadas nos inquéritos. De outro lado, a hostilidade das polícias, especialmente a Civil, frente à interferência do Ministério Público, vista como afronta à autoridade policial.

Ambas as questões foram constatadas no decorrer da pesquisa. De um lado, buscando obter informações junto ao Ministério Público quanto ao exercício do controle externo, fomos encaminhados a uma promotoria específica, com quatro promotores, que teria essa atribuição em Porto Alegre. Como se vê, o trabaIho é visto como "especializado" e não como uma prática que deveria ser levada à frente por todos os integrantes da instituição. O promotor que nos recebeu falou das dificuldades para o exercício das atividades da promotoria, a falta de estrutura, a resistência da polícia. No entanto, quando tentamos obter algum dado mais concreto do trabalho realizado pela promotoria, em dezembro de 2008, nos foi dito que o relatório referente ao ano de 2007 ainda não havia sido concluído e que estariam aguardando a conclusão do relatório do ano de 2008, para encaminhar ambos à Procuradoria de Justiça. Em abril de 2009, entramos em contato com a Procuradoria e a informação recebida é que, até aquele momento, não havia nenhum relatório produzido a respeito do controle externo.

Nas entrevistas realizadas com os delegados de polícia, identifica-se a confusão em relação ao que seria o controle externo exercido pelo MP. No trecho a seguir transcrito, o respondente reclama da falta de uma integração maior do Ministério Público com a polícia no momento da investigação.

Eu ressinto muito com relação especificamente ao Ministério Público, eu vejo que ele teria que trabalhar mais integrado com a polícia, essa necessidade eu vejo, mas integrado no sentido de o Ministério Público fazer o trabalho dele e nós o nosso, eu vejo hoje promotor que quer dar murro na porta, utilizando literalmente a expressão, enquanto ele poderia participar da investigação aqui no departamento de especializada, repassar lá para o promotor da causa, enfim, mandado de busca, mandado de interceptação, fazendo a parte dele. Eu vejo aqui que a gente termina, finaliza investigações, poderia buscar depois a questão da lavagem de dinheiro, mexer no bolso do criminoso, que aí sim tu aniquila com a organização, e isso não vai nunca à frente, e nós não somos pagos pra isso, nós 
vamos voltar àquilo, continuar fazendo o nosso trabalho, então eu vejo que se esse trabalho nascesse integrado, cada um fazendo a sua atribuição e tal, eu vejo um maior sucesso ao final da investigação e um maior sucesso para a sociedade como um todo.

\section{Problemas e Precariedades da Estrutura Policial - o caso do Rio Grande do Sul}

A falta de um orçamento próprio e a insuficiência de recursos para o trabalho da polícia são apontadas pelos policiais como a principal explicação para o trabalho deficitário e pautado pela resposta reativa às ocorrências imediatas, sem que haja um mínimo de planejamento. Como não há planejamento, há uma grande insegurança no trabalho: nunca se sabe se será possível concluir uma investigação e as relações de confiança entre os colegas é que garantem alguma previsibilidade na rotina de trabalho.

A polícia não tem destinação orçamentária própria (é vinculada à Secretaria da Segurança Pública, que tem de manter o IGP, Polícia Civil, Brigada Militar e SUSEPE). Além do recurso ser insuficiente, também é reconhecida, por muitos policiais, a má administração dos gestores (diretores, chefes de polícia), que contribui para a falta de condições de trabalho. Sobre a falta de um planejamento mais amplo e de comunicação entre os gestores e os policiais que atuam na ponta, assim manifestou-se um dos delegados entrevistados:

Embora seguidamente eu abra os jornais e lá está dito que tantos recursos foram entregues na segurança pública, esses recursos não chegam até nós, na verdade hoje eles compram um número $x$ de coletes, mandam, só que não sabem a necessidade mesmo, do que precisa, cada setor da polícia, cada órgão da polícia. O DEIC deveria ter um aparelhamento diferenciado do que outros setores têm, nós temos outro tipo de trabalho, só que não é feito, ou seja, é feito na forma do balaião, se adquire tantas viaturas, só que não se sabe se aquela viatura é necessária para nós. Duas semanas atrás, nós precisávamos cumprir um mandado de busca num sítio em Canela e não tínhamos um veículo apropriado para entrar naquela situação de estrada, e não tinha, nós tivemos que pedir para um empresário uma caminhonete. (...) Em 2005, o DEIC fez um pedido de compra de armamento, pediu fuzil 556, que é o mais apropriado para se utilizar dentro de uma viatura, que é um fuzil menor, com coronha retrátil, fuzil apropriado pro tipo de trabalho que a gente desenvolve. Pasmem, nos foi comprado um outro tipo de fuzil, ou seja, infelizmente eles compram o que está mais barato, o que convém para eles, menos o que realmente nós 
precisamos. Então é assim, há uma ilha que separa a Secretaria dessa ponta da atividade fim da polícia, que muitas vezes não existe, no meu juízo, nenhuma relação, um contato, uma troca de informações de necessidade e tal, eu nunca sentei para conversar com alguém da Secretaria.

A demanda administrativa nas próprias delegacias também é destacada por um dos delegados entrevistados:

A questão dos recursos materiais, como viaturas, manutenção, aí a administração de uma delegacia de polícia ela tira, se fosse só investigação iria ser uma maravilha, mas a administração da delegacia como um todo, falta isso falta aquilo, a administração de pessoal dentro de uma delegacia, a administração de um prédio, faltou água, faltou luz, quebrou ali tem que trocar e tal, e não se tem recursos financeiros para fazer frente a essas demandas diárias, então tudo acaba atrapalhando também a investigação, não tem relação direta mas tem relação, também é uma dificuldade.

Levando em conta o número total de delegados previstos, em torno de 600 para todo o estado do Rio Grande do Sul, formalmente o déficit em abril de 2009 era de 157 delegados. Com relação à carência de pessoal, assim manifestou-se um dos delegados entrevistados:

Bom, várias são as dificuldades que nós enfrentamos para realizar a investigação criminal. A primeira delas não poderia deixar de ser diferente são as nossas carências, dentro das carências listando numa ordem, a primeira delas nosso maior problema é questão de pessoal, número insuficiente de servidores, isso é uma coisa que é pública, notória, todo mundo sabe, enfim, mas não se consegue sequer deter essa redução, hoje nós temos a Polícia Civil do Rio Grande do Sul, cinco mil e seiscentos servidores, em 1980 nós tínhamos seis mil e quatrocentos. Hoje, sem conseguir, da população de sete milhões de habitantes, hoje onze milhões e meio, nós temos menos servidores sem falar aí no que cresceu a criminalidade, enfim, uma série de outras coisas e outros fatores que contribuem para o crescimento da criminalidade, da violência, enfim, nosso maior problema é esse.

A influência de critérios políticos na gestão da segurança pública, como um todo, e da Polícia Civil, em particular, veio à tona quando, em janeiro de 2009, ocorreu a mudança da chefia de polícia. Na visão dos policiais e da própria mídia, o fato teria sido motivado pelo fato de que o Chefe de Polícia não deu andamento à ordem da governadora para cortar o ponto de funcionários grevistas; instaurouse um clima de insegurança e apreensão, aumentando a desmotivação dos policiais, já que não sabiam até quando permaneceriam em suas funções. Um dos delegados entrevistados manifestou-se a respeito do fato: 
Isso aí é arcaico, um absurdo a forma que ocorre hoje a troca de chefia, primeiro, não há uma continuidade nas políticas de segurança, nos projetos, na verdade o cara assume a chefia mas não sabe até quando vai ficar. $\mathrm{E}$ ele é trocado ao bel prazer do governo do Estado, então isso é muito ruim, para nós que estamos na ponta nós não temos segurança, nós não sabemos o que vai acontecer, o Chefe de Polícia na verdade é um homem de confiança da governadora e não da instituição, então é muito complicado trabalhar dessa forma, e é isso que justifica nossos pleitos, a promoção, essa forma que é feita a escolha e a troca de chefia ela impede toda essas coisas que eu te falo, a promoção, compra de material, necessidade de um setor ou outro que deveria ser atendido e que o chefe tem essa consciência mas não consegue impor essa vontade, porque quem decide tudo é o governo do estado, poucos, meia dúzia do governo do estado, então é tudo muito complicado, toda a base da instituição vive uma insegurança tremenda, não há projeto, que eu digo que eu vejo em outras instituições, onde há projetos a longo prazo. O Francisco Mallmann ex-secretário da segurança, que é delegado federal, com todos os defeitos dele ele tinha uma grande qualidade, ele sabia que só ia mudar a cara da Polícia Civil se houvesse planos, projetos de aquisição de delegacias padrão, tudo isso, viaturas boas, armamentos, efetivo maior, essas coisas básicas. Ele tinha projetos, enquanto ele ficou basicamente ele se preocupou com o projeto, e hoje a polícia colhe ainda os projetos que ele fez, só que até ele, seja antes, seja depois, não teve respaldo. E a realidade nossa é que a gente vê há muito tempo é a ausência de projetos, hoje a política de segurança não chega até nós.

Há um reconhecimento generalizado entre os policiais civis gaúchos de que os cargos são ocupados dentro da Polícia Civil apenas em um primeiro momento respeitando o caráter de nomeação por concurso público, mas logo em seguida são os acordos e os interesses políticos que determinam as funções, as tarefas, a valorização ou não do agente.

Segundo um dos policiais entrevistados informalmente, "se prender um deputado hoje, amanha não acorda. Mês passado houve a prisão do filho de um secretario de Estado e a Delegacia quase veio abaixo, com pressão política de todos os lados; em março com certeza trocam o comando da Delegacia". A interferência de interesses políticos sabidamente afeta os resultados da investigação criminal. Comentando o problema das escutas telefônicas, um dos delegados entrevistados critica a gestão do "Guardião" pela Secretaria de Segurança Pública, dando a entender que a mesma seria um órgão político e que o sistema deveria estar diretamente nas mãos da polícia, denotando, ainda, uma dificuldade de admitir a subordinação da atividade policial ao Poder Executivo: 
Nós temos um problema muito sério com relação à interceptação telefônica, com o advento da telefonia móvel celular, uma popularização da telefonia móvel celular, essa ferramenta da interceptação telefônica é a coisa mais importante que a investigação criminal moderna tem, em termos de Brasil, eu estou absolutamente convencido disso aí. Bom, então nós temos que utilizar essa ferramenta, mas a ferramenta não esta à disposição da Polícia Civil, está à disposição da Polícia Civil mas quem gerencia essa ferramenta não é a Polícia Civil, é a Secretaria de Segurança Pública, que ao nosso ver isso é uma coisa que não se concebe sob hipótese alguma, porque a secretaria é um órgão político, partidário, então como é que uma ferramenta dessa ordem vai estar dentro de um órgão político? E mais, eu vejo que não só a Polícia Civil mas até mesmo, até bem pouco tempo, nem sei se já está funcionando, mas eu sei que o Ministério Público adquiriu um Guardião, mas o Ministério Público dependia também do Guardião da Secretaria de Segurança Pública, ou seja, um órgão político. Se o Ministério Público estivesse investigando - e via de regra é o segundo andar da sociedade, o colarinho branco e tal - o poder político estava sabendo quem é que ele estava escutando, quem é que estava investigando, então eu vejo que isso é uma dificuldade por demais, até frustrante.

Quanto à produção do inquérito policial, uma das dificuldades apontadas por vários policiais é a desconfiança das pessoas, que deixam de depor por medo de represálias na comunidade onde moram. Os próprios delegados reconhecem a incapacidade da polícia para oferecer a devida proteção às testemunhas em caso de necessidade:

Não há o que fazer. É tirar a pessoa de circulação até que termine o inquérito e depois dizer 'até logo, muito obrigado'. A polícia não funciona como nos filmes. Não há como garantir a segurança de quem está sendo ameaçado.

Além disso, o volume de ocorrências e inquéritos é muito superior à capacidade operacional da Polícia. Os que têm indício de autoria (maior probabilidade de solução) ou que têm muita pressão política/midiática são os atendidos.

Os trechos acima reproduzidos dão conta, entre outras coisas, dos dilemas institucionais, da crise do modelo e dos problemas de precariedade de pessoal e estrutura em que se encontra a Polícia Civil do Rio Grande do Sul. Anos de incompetência gerencial, desmandos administrativos, ingerência de interesses políticos na gestão da segurança pública, fizeram com que a instituição se encontre hoje em uma situação de penúria e precariedade. Nesse contexto, alguns policiais se empenham para cumprir da melhor forma suas atribuições, enquanto outros se aproveitam da falta de condições de trabalho e de controle para fazer o mínimo possível, aguardando a aposentadoria ou preparando-se para 
um concurso que garanta melhores condições de trabalho.

Diante da precariedade de meios, boa parte das previsões legais que estabelecem os procedimentos a serem realizados durante o inquérito policial não são seguidos, tendo como justificativa a necessidade de lidar com as dificuldades cotidianas e responder à demanda imediata. Tal como colocado, o modelo do inquérito policial não contribui para o equacionamento das dificuldades, pois reforça um perfil burocrático e bacharelesco em detrimento das atividades de investigação policial. Diante da alegação de que o problema seria a falta de estrutura, constata-se que, ainda que a estrutura fosse mais adequada, se poderia questionar o modelo atual pelas apontadas e verificadas dificuldades de integração entre as polícias e destas com os demais órgãos do Sistema de Justiça Criminal.

A pesquisa no interior de instituições corporativas como é a Polícia Civil se depara permanentemente com interesses particularistas que, muitas vezes, se opõem à possibilidade de uma reforma mais ampla. No entanto, é tal a situação da Polícia Civil gaúcha em termos de precariedade estrutural e falta de reconhecimento público, que acreditamos haver hoje, no interior da instituição, uma abertura para a reflexão e o debate a respeito de possíveis mudanças. Foi o que se constatou ao ouvir os policiais a respeito da estrutura das polícias, assim como sobre a ausência de um controle efetivo por parte de quem tem a atribuição constitucional para exercê-lo.

A investigação sobre a Polícia Civil, no âmbito das ciências sociais, vem avançando no Brasil, viabilizada pelos 21 anos de democracia que marcam esse período da história brasileira. Já é tempo de avançar para além das constatações e, em parceria com gestores públicos comprometidos com as necessárias reformas e policiais que compreendem a importância de suas atribuições para a construção de uma sociedade verdadeiramente democrática, definir os contornos de uma nova polícia, a serviço do esclarecimento dos fatos e da garantia dos direitos fundamentais. Para tanto, estrutura e formação policial que rompam com uma cultura institucional construída em meio à precariedade e ao descontrole ainda são fundamentais, mas é necessário, também, repensar as relações institucionais entre as polícias e destas com o Ministério Público e o Poder Judiciário e redefinir as atribuições de cada um desses órgãos no sentido do aperfeiçoamento dos mecanismos de apuração e processamento dos eventos criminais.

Abstract: This article first discusses the model of pre-processual investigation procedure adopted in Brazil aimed at strengthening a bureaucratic and scholastic profile rather than the activities of police investigation. We discuss institutional relationships established between the civil police and other institu 
tions of public security system and criminal justice, and concludes that lack of systemic integration between different areas of Criminal Justice has just to multiply the sources of tension between their agents, and undermines the efficiency of the system as a whole. Finally, we present excerpts from interviews with Police Officers working in the city of Porto Alegre - RS, in order to understand the perceptions of these operators in the criminal justice system about the dilemmas faced in the production of investigation, both in relation to other institutions and about the precariousness material and human evidences in the civil police in Rio Grande do Sul.

Keywords: Police Inquiry, Criminal Investigation, Police Officers, Criminal Procedure.

\section{Referências Bibliográficas}

Adorno, Sérgio (1994) "Violência, controle social e cidadania: Dilemas de administração da Justiça Criminal no Brasil". Revista Crítica de Ciências Sociais, n. 41. Coimbra.

Azevedo, Rodrigo Ghiringhelli et al (2010) "O Inquérito Policial na Cidade de Porto Alegre" in Michel Misse, $O$ inquérito policial no Brasil: Uma pesquisa empírica. Rio de Janeiro: NECVU/IFCS/UFRJ, Booklink.

Costa, Arthur Trindade Maranhão et al (2010) "A discricionaridade no sistema de justiça criminal: uma análise policial no distrito federal" in Michel Misse, $O$ inquérito policial no Brasil: Uma pesquisa empírica. Rio de Janeiro: NECVU/IFCS/ UFRJ, Booklink.

Kant de Lima, Roberto (1995) A Polícia da Cidade do Rio de Janeiro - seus dilemas e paradoxos. Rio de Janeiro: Ed. Forense, $2^{\text {a }} \mathrm{Ed}$.

Lemgruber, Julita, Musumeci, Leonarda \& Cano, Ignacio (2003) Quem Vigia os Vigias? Rio de Janeiro: Ed. Record.

Lopes Jr, Aury (2006) Sistemas de investigação preliminar no processo penal. Rio de Janeiro: Lumen Juris.

Misse, Michel (2008) "A construção social do crime no Brasil: Esboços de uma interpretação" in Michel Misse (org), Acusados e Acusadores: Estudos sobre ofensas, acusações e incriminações. Rio de Janeiro: REVA/ FAPERJ.

(2010) "Introdução" in Michel Misse, O inquérito policial no Brasil:

Uma pesquisa empírica. Rio de Janeiro: NECVU/IFCS/UFRJ, Booklink. 
(2010) "O inquérito policial no Rio de Janeiro: Mudanças recentes, alcances, tradições e especificações" in Michel Misse, $O$ inquérito policial no Brasil: Uma pesquisa empírica. Rio de Janeiro: NECVU/IFCS/UFRJ, Booklink.

Ratton, José Luiz et al (2010) "Refletindo sobre o inquérito policial na cidade do Recife: uma pesquisa empírica" in Michel Misse, $O$ inquérito policial no Brasil: Uma pesquisa empírica. Rio de Janeiro: NECVU/IFCS/UFRJ, Booklink.

Santos, Boaventura de Sousa et al (1996) Os tribunais nas sociedades contemporâneas - $O$ caso português. Porto: Afrontamento.

Vargas, Joana Domingues et al (2010) "Uma abordagem empírica do inquérito policial: o caso de Belo Horizonte" in Michel Misse, O inquérito policial no Brasil: Uma pesquisa empírica. Rio de Janeiro: NECVU/IFCS/UFRJ, Booklink. 